\title{
Model Irigasi Hemat Air Perpaduan System of Rice Intensification (SRI) dengan Alternate Wetting and Drying (AWD) pada Padi Sawah
}

\author{
Water-Saving Irrigation Model Combining System of Rice Intensification \\ (SRI) with Alternate Wetting and Drying (AWD) for Paddy Field
}

\author{
Muh. Bagus Budianto' ${ }^{1)}$, Anid Supriadi ${ }^{1}$, Syamsul Hidayat ${ }^{1}$, Salehudin $^{1}$ \\ ${ }^{1}$ Jurusan Teknik Sipil Fakultas Teknik Universitas Mataram, Indonesia
}

\section{Article info:}

Kata kunci:

alternate wetting and drying, irigasi hemat air, konvensional, system of rice intensification

Keywords:

alternate wetting and drying, conventional, system of rice intensification, water saving irrigation

Article history:

Received: 03-11-2020

Accepted: 29-11-2020

${ }^{*}$ Koresponden email: mbagusbudianto@unram.ac.id

\begin{abstract}
Abstrak
Kebutuhan air terbesar adalah sektor pertanian sekitar $80 \%$ dari total kebutuhan air. Sistem irigasi konvensional saat ini merupakan sistem yang boros air. Tujuan penelitian ini adalah membandingkan kebutuhan air dan hasil produksi sistem konvensional dengan sistem irigasi hemat air perpaduan System of Rice Intensification (SRI) dengan Alternate Wetting and Drying (AWD). Model yang digunakan berupa pot dengan pola penanaman mengikuti metode SRI sedangkan pengaturan pemberian airnya mengikuti sistem AWD. Terdapat enam variasi yang digunakan dalam model. Hasil penelitian menunjukkan bahwa pemberian air irigasi pada variasi 1 (kedalaman air $-5 \mathrm{~cm}$ ) dan variasi 2 (kedalaman air -10) dapat menghemat air $33.53 \%$ dan $19.55 \%$, dengan produksi hasil tanaman meningkat $29.83 \%$ dan $21.39 \%$ lebih besar dibanding variasi 6 (metode konvensional). Untuk variasi 3 (kedalaman -15 $\mathrm{cm})$ dan 4 (kedalaman $-17 \mathrm{~cm}$ ) tidak disarankan untuk diaplikasikan karena walaupun ada penghematan air namun hasilnya lebih kecil dibanding variasi 6 . Variasi 1 juga memiliki produktivitas air tertinggi yaitu $11.93 \mathrm{gr} / \mathrm{lt}$, disusul variasi 2 sebesar $9.22 \mathrm{gr} / \mathrm{lt}$, sedangkan untuk variasi 6 produktivitas airnya sebesar $6.11 \mathrm{gr} / \mathrm{lt}$.
\end{abstract}

\begin{abstract}
The greatest need for water is the agricultural sector, which is about $80 \%$ of the total water demand. The current conventional irrigation system is a water wasteful system. This study compares the water requirements and yields of conventional rice production systems with a water-saving irrigation system, a combination of System of Rice Intensification (SRI) and Alternate Wetting and Drying (AWD). The model used is a pot with a planting pattern following the SRI method, while the water supply arrangement follows the AWD system. There are six variations used in the model. The results showed that giving irrigation water at variation 1 (water depth $-5 \mathrm{~cm}$ ) and variation 2 (water depth -10) could save water $33.53 \%$ and $19.55 \%$, with crop production increasing $29.83 \%$ and $21.39 \%$ greater than variation 6 (conventional method). For variations 3 (depth $-15 \mathrm{~cm}$ ) and 4 (depth $-17 \mathrm{~cm}$ ) it is not recommended to apply because even though there is water savings, the results are smaller than variation 6 . Variation 1 also has the highest water productivity, namely $11.93 \mathrm{gr} / 1$, followed by variation 2 amounting to $9.22 \mathrm{gr} / \mathrm{l}$, while for variation 6 the water productivity is $6.11 \mathrm{gr} / 1$.
\end{abstract}

Kutipan: Budianto, M. B., Supriadi, A., Hidayat, S., Salehudin. (2020). Model Irigasi Hemat Air Perpaduan System of Rice Intensification (SRI) dengan Alternate Wetting and Drying (AWD) pada Padi Sawah. Jurnal Teknik Pengairan. https://doi.org/10.21776/ub.pengairan.2020.011.02.06 


\section{Pendahuluan}

Salah satu permasalahan sumberdaya air adalah kebutuhan air yang terus meningkat berbanding lurus dengan bertambahnya jumlah penduduk, sehingga kebutuhan akan pangan juga semakin meningkat. Saat ini kebutuhan air didominasi oleh kebutuhan air pada sektor pertanian. Hal ini dikarenakan sistem irigasi sebagian besar petani masih menggunakan sistem penggenangan secara terus menerus (metode konvensional) ketika menanam padi.

Sistem irigasi konvensional adalah sistem irigasi yang boros air. Kondisi tersebut diperparah dengan perilaku sebagian petani yang masih memberikan air pada lahan mereka secara berlebihan. Kondisi ini menyebabkan sawah yang berada di hilir mengalami kekurangan air. Salah satu usaha untuk memperluas areal irigasi yang terairi adalah dengan menerapkan sistem irigasi hemat air di lahan padi sawah. Sistem irigasi hemat air adalah sistem irigasi yang pemberian airnya dilakukan secara terputus-putus (intermitten). Pada prinsipnya teknologi irigasi hemat air adalah mengurangi kebutuhan air yang tidak produktif seperti rembesan, evaporasi dan perkolasi. Disamping itu dalam irigasi hemat air dipertahankan aliran transpirasi (Hilman 2011).

Metode SRI merupakan teknologi budidaya alternatif untuk meningkatkan produksi padi melalui manajemen tanaman, tanah, hara dan air. Sistem ini pertama kali dikembangkan di Madagaskar oleh Father Henri de Laudanie pada tahun 1980. Teknologi budidaya SRI telah diujicoba dan dikembangkan di beberapa negara Asia Selatan, seperti India, Bangladesh dan Srilangka, di samping di Kawasan Asia Tenggara Thailand, Philipina dan Cina (Anugrah, I.S, Sumedi Sumedi, Wardana 2008).

Pada tahun 1999 metode SRI pertama dikembangkan di Indonesia oleh Lembaga Penelitian dan Pengembangan Pertanian di wilayah Sukamandi Provinsi Jawa Barat dan menghasilkan 6.2 ton/ha pada musim kemarau dan 8.2 ton/ha pada musim penghujan. Menurut Sato Shuici (2007) daerah semi kering di Indonesia seperti NTB dan NTT yang memiliki curah hujan yang sedikit cocok untuk dikembangkan metode ini, karena sistem ini dapat menghemat air sampai $40 \%$. Sedangkan menurut (Rizal, YBC, and Rizalihadi 2014) yang didasarkan pada prinsip keseimbangan air metode SRI lebih hemat 35\% daripada metode konvensional.

Penelitian lain menunjukkan hasil produktivitas air yang tinggi dan hemat dalam penggunaan air dilakukan oleh (Fuadi, Purwanto, and Tarigan 2016) ketika meneliti kebutuhan air dan produktivitas air metode SRI dan konvensional dengan irigasi pompa. Penelitian tentang jarak tanam pada sistem SRI memberikan hasil jarak tanam $25 \times 25 \mathrm{~cm}$ dengan waktu pengeringan lima hari hasilnya paling besar yaitu 7.85 ton/ha dibanding perlakuan yang lain (Habibie 2011). Sedangkan penelitian evaluasi untung rugi penerapan metode SRI menunjukkan hasil produksi SRI lebih tinggi sekitar $40 \%$ di banding metode konvensional khusus untuk yang menjalankan sistem SRI lebih dari dua kali (Kurniadiningsih 2012).

Teknologi irigasi hemat air yang lain adalah dengan pengelolaan air yang disebut alternate wetting and drying (AWD) atau dikenal dengan istilah pengairan basah kering (PBK). Negaranegara seperti Cina, India dan Philipina dan Indonesia telah menerapkan metode ini. Metode ini menambah efisiensi penggunaan air dan tidak menyebabkan punurunan hasil. Metode ini sawah digenangi sampai setinggi $5 \mathrm{~cm}$ kemudian air dibiarkan turun hingga kedalaman $15 \mathrm{~cm}$ di bawah permukaan tanah, kemudian diairi lagi sampai mencapai elevasi $5 \mathrm{~cm}$ di atas tanah. Pada waktu tanaman padi mulai berbunga ketinggian air dipertahankan hingga kedalaman $5 \mathrm{~cm}$, kemudian pada fase pengisian dan pematangan bulir padi AWD diberlakukan kembali (Hilman 2011).

Menurut (Sujono 2012) berdasarkan pada nilai koefisien tanam (kc) pemberian air sistem AWD dapat menghemat air lebih dari 30\% dibandingkan dengan sistem tradisional.Pada pengamatan metode irigasi air sawah menggunakan metode irigasi berbeda, penghematan air menggunakan metode AWD dapat menghemat air 55,03\% (Adriati and Sujono 2008).

Dibandingkan dengan metode intermitten atau irigasi terputus dan irigasi dengan penggenangan secara menerus metode AWD dapat mengahasilkan padi lebih banyak, yaitu sebesar Rp 16.1 juta/ha sedangkan metode intermitten sebesar Rp 14.1 juta/ha dan metode penggenangan Rp 13.4 juta/ha (Muh. Taufik Arafah, Basir, and Fadjry 2014). Selanjutnya penelitian lain tentang koefisien tanaman padi dengan berbagai metode menunjukkan metode AWD merupakan metode paling efisien dibanding metode konvensional dan Mid Summer Drainage (MSD). Metode AWD dengan bahan organik $40 \%$ memiliki nilai koefisien rerata sebesar 2.42 . Nilai koefisien tanaman 
rerata terkecil adalah dengan metode AWD berbahan organik 60\% yaitu sebesar 1.98 (Chlarrasinta 2018).

Tujuan penelitian ini adalah untuk mengetahui jumlah air yang dibutuhkan pada sistem irigasi hemat air perpaduan metode SRI dan AWD dengan berbagai variasi pemberian air irigasi setelah air kedalaman tertentu dan untuk mengetahui produktivitas airnya dibanding dengan menggunakan metode konvensional.

\section{Bahan dan Metode}

Penelitian ini dilakukan di Desa Sintung, Kecamatan Pringgarata, Kabupaten Lombok Tengah dengan menggunakan wadah (ember) sebagai media tanam dimana pola tanam yang diterapkan mengikuti sistem SRI sedangkan pola pemberian airnya dengan metode AWD yang ditempatkan pada lokasi sawah yang digunakan sebagai lokasi penelitian. Peta lokasi dapat dilihat pada Gambar 1.

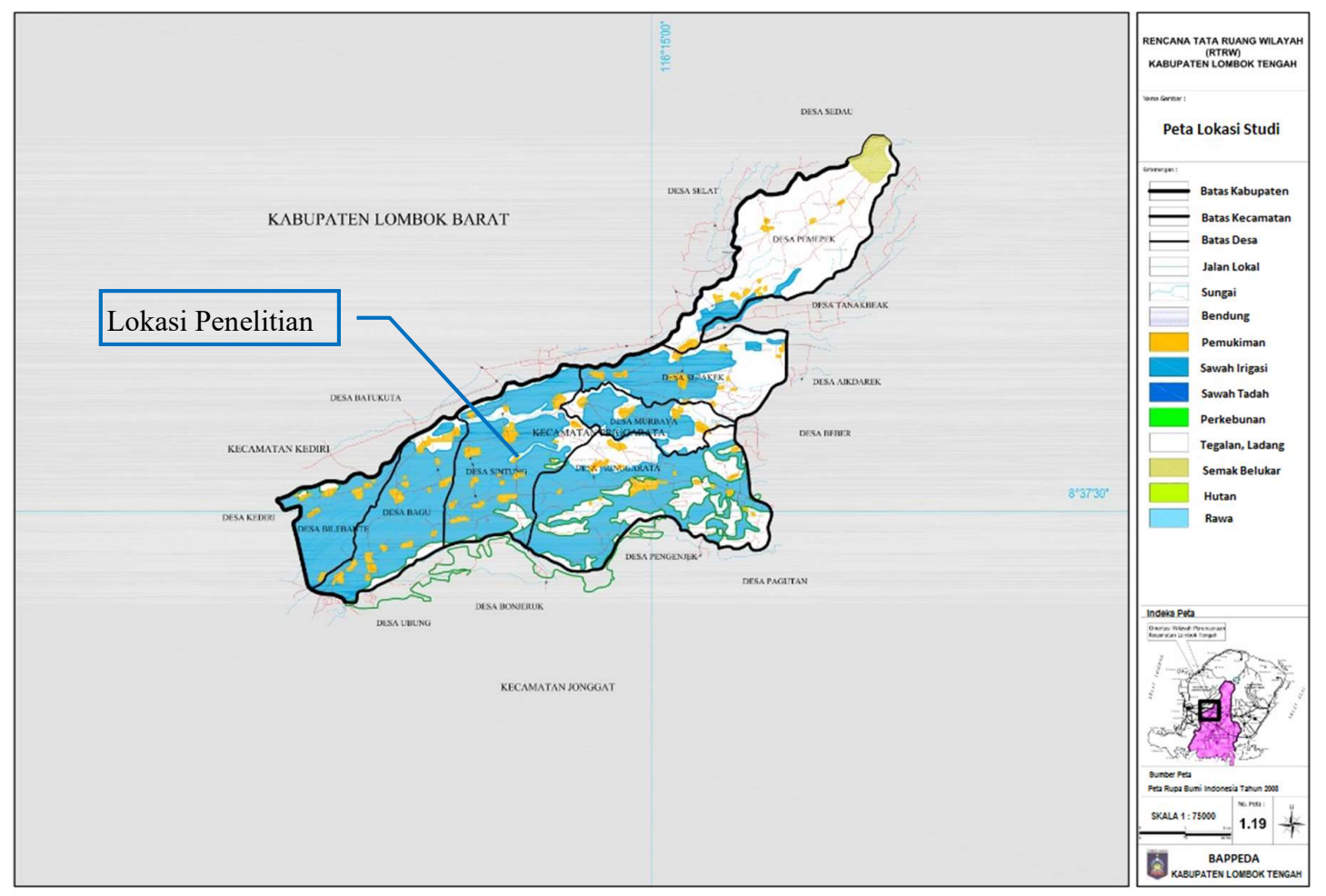

Gambar 1. Lokasi penelitian

\subsection{Metode System of Rice Intensification (SRI)}

Dalam penerapan metode SRI ada beberapa hal penting yang harus diperhatikan yaitu (Anugrah, I.S, Sumedi Sumedi, Wardana 2008):

1. Bibit dipindahkan ke lahan ketika usia muda yaitu umur 8 - 15 hari. Hal ini dilakukan agar produksi batang dan akar dapat tumbuh maksimal selama fase pertumbuhan sehingga jumlah anakannya optimal.

2. Bibit tidak ditanam secara berumpun melainkan satu-satu, sehingga ruang tumbuh, cahaya dan unsur hara dalam (Munarso 2011)tanah untuk pertumbuhan terpenuhi dengan baik.

3. Jarak antar tanaman minimal $25 \times 25 \mathrm{~cm}$ agar cukup ruang untuk pertumbuhan akar tanaman sehingga dapat merangsang tumbuhnya anakan yang banyak

4. Lahan tidak digenangi secara menerus, setelah diberi air irigasi setinggi $1-3 \mathrm{~cm}$ dibiarkan tanah mengering hingga retak rambut baru kemudian diberi air lagi. Hal ini dimaksudkan untuk terjadinya proses oksidasi di zona perakaran sehingga tanah menjadi subur dan akar tanaman 
dapat tumbuh lebat. Metode ini dilakukan terus kecuali pada fase pembungaan dan pematangan buah, diusahakan lahan selalu tergenang agar hasil produksi tidak menurun.

5. Penyiangan dilakukan 2 - 3 kali untuk menghilangkan gulma dan memberi ruang untuk aerasi tanah selama masa pertumbuhan

6. Agar struktur tanah dapat diperbaiki dan untuk penyediaan unsur hara disarankan menggunakan pupuk kompos

\subsection{Metode Alternate Wetting and Drying (AWD)}

Sistem pengairan AWD atau pengairan basah-kering merupakan pengairan dengan penggenangan air terputus. Metode ini pada awalnya sama dengan metode-metode yang lain, yaitu lahan digenangi air setinggi $2-5 \mathrm{~cm}$, kemudian pemberian air dihentikan dan dibiarkan elevasi muka air turun secara alami. Pemberian air irigasi diberikan kembali hingga ketinggian awal ketika elevasi muka air di lahan turun hingga batas kedalaman $-10 \mathrm{~cm}$ sampai dengan $-15 \mathrm{~cm}$ dari muka tanah. Untuk memonitor elevasi muka air di lahan menggunakan bantuan paralon dengan panjang 35 cmyang di tanam dilahan dengan dinding paralon yang masuk ke tanah sekitar $20 \mathrm{~cm}$ dan dinding paralonnya diberi lubang. Sesaat setelah paralon ditanam di lahan, tanah yang berada di dalam paralon dikeluarkan, sehingga akan nampak elevasi muka air di dalam paralon yang mencerminkan elevasi muka air di lahan. Elevasi muka air dalam paralon diukur kedalamannya dengan menggunakan alat ukur penggaris atau meteran. Pengairan sistem ini dilaksanakan dari tanaman berumur 7 - 10 hari sampai dengan 7 hari sebelum dipanen, kecuali 7 hari sebelum dan setelah fase pembungaan lahan selalu digenangi agar tidak mengurangi hasil produksi (Munarso 2011). 2020):

Beberapa faedah pengairan berselang dan metode basah kering (Kementerian Pertanian

1. Dibandingkan metode konvensional dapat menghemar air $15 \% \mathrm{~s} / \mathrm{d} 40 \%$.

2. Bertambahnya angka produktivitas air

3. Dapat mencegah beberapa hama nematode di zona perakaran dan hama wereng coklat

4. Emisi gas metan dapat diturunkan

5. Kualitas gabah dapat ditingkatkan

6. Kondisi tanah yang berubah-ubah dari basah ke kering dapat menyebabkan meningkatkan terserapnya unsur hara

7. Terakumulasinya besi $(\mathrm{Fe})$ dalam tanah yang menyebabkan tanaman menjadi beracun dapat dikurangi

8. Penggunaan gasrok/landak dalam penyiangan sekaligus dapat mencampur pupuk dan tanah, sehingga efisien

9. Sistem perakaran lebih dalam sehingga batang padi lebih kuat dan tidak mudah rubuh

\subsection{Rancangan model}

Model yang digunakan pada penelitian ini berupa pot setinggi $25 \mathrm{~cm}$ yang diisi tanah setinggi $20 \mathrm{~cm}$ sejumlah 30 buah yang terbagi dalam 6 variasi. Peralatanyang digunakan untuk mengukur air yang diberikan dengan menggunakan gelas ukur dan untuk mengontrol kedalaman air dengan menggunakan paralon diameter 1 inch dengan panjang $25 \mathrm{~cm}$ yang dilubangi di bagian bawah yang ditanam di masing-masing sampel uji.

Dalam penelitian ini dibagi menjadi enam variasi dengan masing-masing variasi berjumlah lima sampel uji. Variasi yang dimaksud disini adalah variasi pemberian air irigasi setelah kedalaman air mencapai kedalaman tertentu dalam sistem AWD. Variasi kedalaman air sistem AWD yang dilakukan yaitu sebagai berikut :

1. Variasi 1 : pemberian air irigasi setelah kedalaman air $-5 \mathrm{~cm}$ dari muka tanah (pot $1-5$ )

2. Variasi 2 : pemberian air irigasi setelah kedalaman air $-10 \mathrm{~cm}$ dari muka tanah (pot $6-10$ )

3. Variasi 3 : pemberian air irigasi setelah kedalaman air $-15 \mathrm{~cm}$ dari muka tanah (pot $11-15$ )

4. Variasi 4 : pemberian air irigasi setelah kedalaman air $-17 \mathrm{~cm}$ dari muka tanah (pot $16-20$ )

5. Variasi 5 : pemberian air irigasi kombinasi kedalaman air berdasar usia tanaman (pot $21-25$ ) yaitu:

a. Umur 1-21 mengikuti variasi 1 
b. Umur $22-51$ mengikuti variasi 2

c. Umur $52-62$ mengikuti variasi 3

d. Umur $63-76$ mengikuti variasi 4

6. Variasi 6 : Sistem konvensional dengan penggenangan terus menerus (pot 26-30)

Model ditempatkan dilahan sawah, sehingga faktor lingkungan seperti suhu, kelembaban udara dan penyinaran matahari masing-masing model mendapatkan perlakuan yang sama. Data klimatologi stasiun yang terdekat dengan lokasi penelitian yaitu Stasiun Kopang pada saat penelitian disajikan pada Tabel 1 .

Tabel 1. Data klimatologi rata-rata Stasiun Kopang pada saat penelitian

\begin{tabular}{lcccccc}
\hline Bulan & Periode & $\begin{array}{c}\text { Penguapan } \\
(\mathrm{mm})\end{array}$ & $\begin{array}{c}\text { Suhu } \\
\left({ }^{\circ} \mathrm{C}\right)\end{array}$ & $\begin{array}{c}\text { Kecepatan } \\
\text { Angin } \\
(\mathrm{km} / \text { hari })\end{array}$ & $\begin{array}{c}\text { Kelembaban } \\
\text { Relatif }(\%)\end{array}$ & $\begin{array}{c}\text { Penyinaran } \\
\text { Matarahari } \\
\text { n/N (\%) }\end{array}$ \\
\hline April & II & 3,99 & 26,73 & 59,26 & 89,29 & 51,43 \\
\hline \multirow{2}{*}{ Mei } & I & 3,97 & 26,74 & 53,86 & 90,06 & 48,59 \\
\cline { 2 - 7 } & II & 3,83 & 26,41 & 50,68 & 90,24 & 48,94 \\
\hline \multirow{2}{*}{ Juni } & I & 3,38 & 26,18 & 50,15 & 90,61 & 44,01 \\
\cline { 2 - 7 } & II & 3,31 & 26,02 & 56,81 & 90,23 & 44,39 \\
\hline \multirow{2}{*}{ Juli } & I & 3,46 & 25,64 & 67,28 & 90,36 & 45,12 \\
\hline & II & 3,44 & 25,66 & 69,5 & 90,34 & 49,48 \\
\hline
\end{tabular}

Penelitian di fokuskan pada perbedaan volume air yang diberikan masing-masing variasi dan implikasinya terhadap hasil produksinya.

\subsection{Metode pelaksanaan}

Penelitian ini dilakukan dengan langkah-langkah sebagai berikut :

1. Pot diisi dengan tanah sawah sebagai media tanam dan di bagian tepi ditanam pipa yang telah dilubangi untuk mengontrol tinggi air

2. Bibit di tanam di pot ketika umur 10 hari dengan sistem penanaman mengikuti sistem SRI yaitu satu pot satu bibit.

3. Setiap pot diberi paralon dengan ukuran 1 inch yang bawahnya telah dilubangi dan tanah dalam paralon dikeluarkan.

4. Pengukuran kedalaman air dalam pot dilakukan dengan pengukuran elevasi muka air dalam pipa dilakukan setiap hari

5. Penambahan air dalam pot diatur berdasarkan variasi di atas

6. Sistem pemberian air secara AWD dihentikan dan diganti dengan penggenangan setinggi 2 $\mathrm{cm}$ selama masa pembungaan dan pematangan buah.

7. Padi di panen ketika sudah menguning dan hasilnya untuk masing-masing pot ditimbang.

Gambar 2 menunjukkan beberapa dokumentasi pada proses pelaksanaan penelitian, dimulai dari pemindahan bibit, pemberian air dan pengukuran hasil.

\section{Hasil dan Pembahasan}

\subsection{Pola kedalaman air}

Kedalaman air dimasing-masing benda uji diukur setiap hari untuk mengetahui perubahan kedalaman air yang terjadi dari awal tanam hingga usia 76 hari setelah tanam. Pola perubahan kedalaman air untuk masing-masing variasi disajikan pada Gambar 3. 


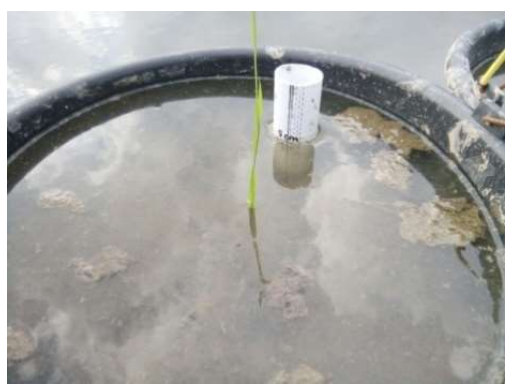

a. Pemindahan bibit

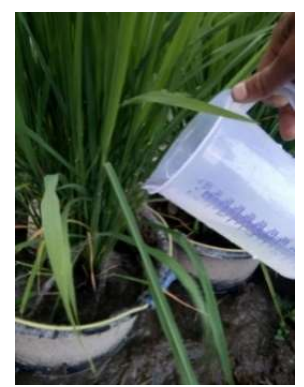

b. Pemberian air

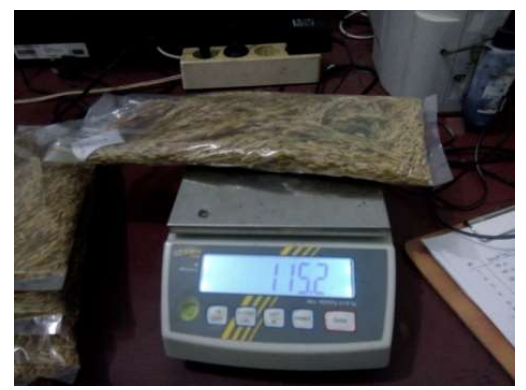

c. Pengukuran hasil

Gambar 2. Proses penelitian

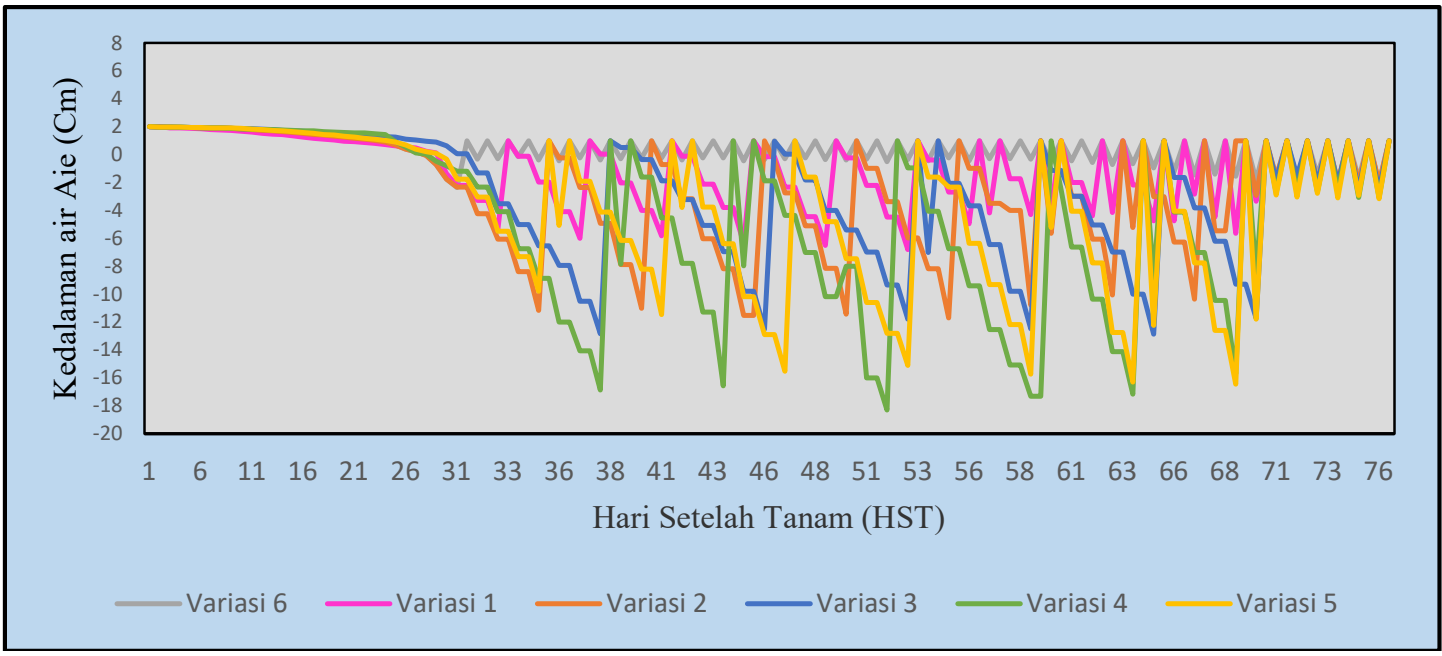

Gambar 3. Pola kedalaman air

Berdasarkan Gambar 3 dapat dilihat pola kedalaman air untuk semua variasi dari awal tanam sampai panen. Pola yang terbentuk dari padi umur 1 HST s/d 30 HST semua variasi menunjukkan tren yang tidak jauh berbeda. Kemudian saat padi berumur 31 HST - 70 HST polanya sangat beragam, semakin besar variasi atau semakin dalam elevasi muka air sistem AWD periode waktunya juga semakin panjang, pada masa ini tanaman padi berada dalam fase pertumbuhan. Selanjutnya ketika umur 70 HST s/d 76 HST polanya menunjukkan tren yang sama, hal ini karena memasuki fase pembungaan dan pematangan buah yang merupakan fase yang krusial terhadap hasil produksi sehingga dilakukan penggenangan.

Kondisi lingkungan berdasarkan data klimatologi yang terdekat dengan lokasi penelitian yaitu Stasiun Kopang menunjukkan pada saat pelaksanaan penelitian suhu berkisar antara $25.64 \mathrm{~s} / \mathrm{d}$ 26.74 dengan suhu rata-rata $26.20^{\circ} \mathrm{C}$, kelembaban udara antara $89.29 \mathrm{~s} / \mathrm{d} 90.61$ dengan rata-rata $90.16 \%$, penguapan $3.31 \mathrm{~s} / \mathrm{d} 3.99$ dengan rata-rata 3.63 dan penyinaran matahari antara $44.01 \mathrm{~s} / \mathrm{d}$ 51.43 dengan rata-rata $47.42 \%$.

\subsection{Frekuensi pemberian air, volume air dan efisiensi}

Berdasarkan pada pencatatan pemberian air, dilakukan analisis terhadap frekuensi pemberian air dan volume air yang telah diberikan dari awal tanam hingga panen. Volume total air yang telah diberikan untuk masing-masing variasi, dibandingkan dengan volume total air metode konvensional (variasi 6) sehingga dapat dianalisis efisiensi yang dihasilkan pada Tabel 2. 
Tabel 2. Frekuensi pemberian air, volume pemberian air dan penghematan air

\begin{tabular}{ccccc}
\hline Variasi & $\begin{array}{c}\text { Frekuensi } \\
\text { pemberian air }\end{array}$ & $\begin{array}{c}\text { Volume total } \\
\text { air (liter) }\end{array}$ & $\begin{array}{c}\text { Perbedaan volume air } \\
\text { dengan variasi 6 (liter) }\end{array}$ & $\begin{array}{c}\text { Penghematan air } \\
(\%)\end{array}$ \\
\hline 1 & 23 & 10.03 & $-5,06$ & 33.53 \\
\hline 2 & 18 & 12.14 & $-2,95$ & 19.55 \\
\hline 3 & 16 & 12.05 & $-3,04$ & 20.15 \\
\hline 4 & 13 & 13.57 & $-1,52$ & 10.07 \\
\hline 5 & 18 & 13.42 & $-1,67$ & 11.07 \\
\hline 6 & 45 & 15.09 & 0 & - \\
\hline
\end{tabular}

Tabel 2 menunjukkan bahwa pada variasi 1 frekuensi pemberian air dari awal tanam hingga panen terbesar kedua yaitu $23 \mathrm{kali}$, sedangkan volume total air yang diberikan terkecil yaitu 10.03 liter. Pada variasi 6 (metode konvensional) terlihat bahwa frekuensi pemberian air dan volume total air yang paling dengan frekuensi 45 kali dan jumlah total air 15.09 liter.

Pada Tabel 2 terlihat penghematan air yaitu harga mutlak volume air variasi 6 dengan variasi yang lain dibagi dengan volume air variasi 6 dikali $100 \%$ menunjukkan bahwa variasi 1 dapat menghemat air $33.53 \%$, sedangkan untuk variasi 2 dan variasi 3 penghematan airnya hampir sama berturut-turut adalah $19.55 \%$ dan $20.15 \%$, untuk variasi 4 air dapat dihemat $10.07 \%$.

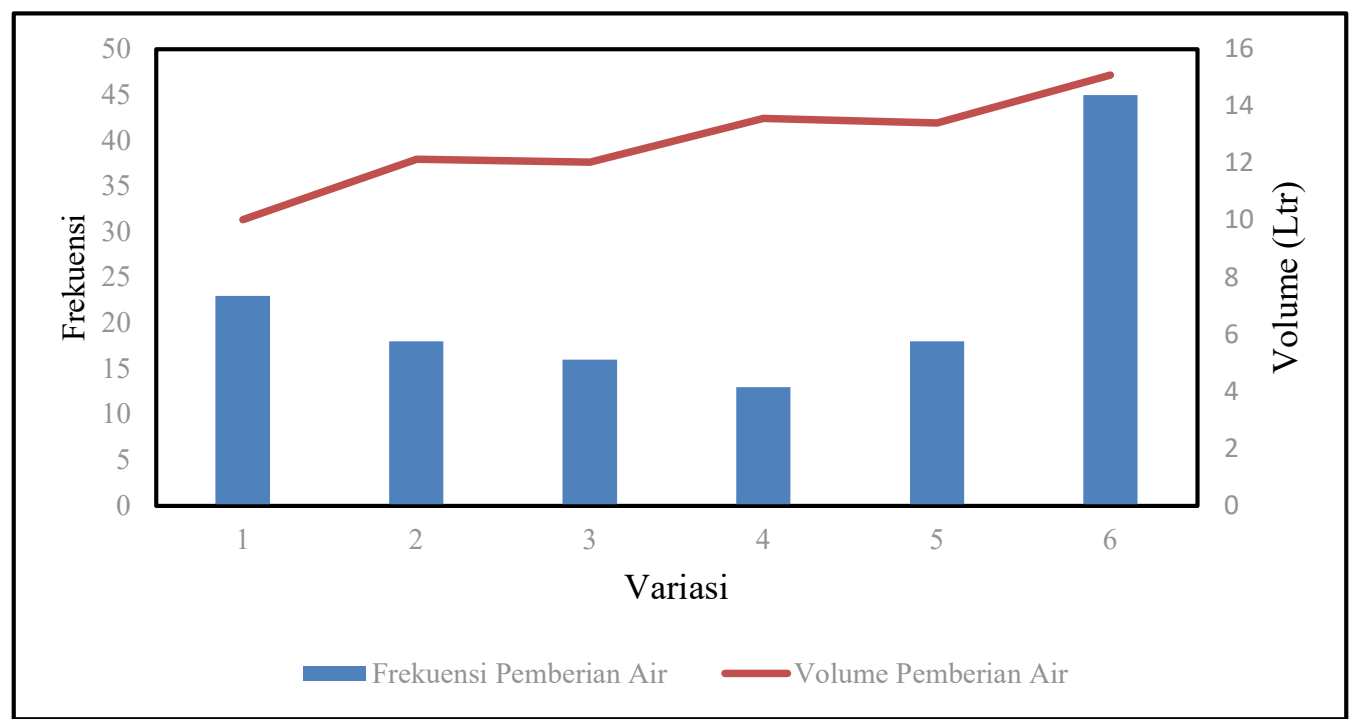

Gambar 4. Grafik hubungan variasi dengan frekuensi dan volume pemberian air

Gambar 4 menunjukkan grafik hubungan antara variasi dengan frekuensi dan volume air yang diberikan dari awal tanam hingga panen. Berdasarkan Gambar 4 nampak bahwa untuk variasi 1 sampai dengan variasi 4 frekuensi pola pemberian air menurun, kondisi ini berbanding terbalik dengan volume air yang diperlukan padi dari awal tanam hingga panen yaitu menunjukkan tren yang naik. Sehingga dapat disimpulkan semakin dalam elevasi muka air metode AWD kebutuhan airnya semakin besar, hal ini dikarenakan walaupun interval pemberian airnya lebih lama, namun dalam sekali mengisi jumlah air yang diberikan lebih banyak. Untuk variasi 5 frekuensi pemberian airnya sama dengan variasi 2, akan tetapi volume air yang dibutuhkan lebih banyak. Sedangkan untuk variasi 6 yaitu metode konvensional frekuensi pemberian air dan volume air yang dibutuhkan paling tinggi, hal ini untuk menjaga agar kondisi lahan tetap tergenang. 


\subsection{Produktivitas air}

Produksi padi diperoleh dari menimbang hasil masing-masing sampel uji dan kemudian dirata-ratakan per variasi. Produktivitas air dianalisis dengan membandingkan hasil produksi ratarata dengan kebutuhan air rata-rata mulai dari bibit ditanam hingga panen pada masing-masing variasi. Hasil selengkapnya disajikan pada Tabel 3.

Tabel 3. Hasil produksi dan produktivitas air

\begin{tabular}{cccccc}
\hline Variasi & $\begin{array}{c}\text { Hasil produksi } \\
\text { rata-rata (gr) }\end{array}$ & $\begin{array}{c}\text { Perbedaan produksi } \\
\text { dengan variasi 6 } \\
\text { (gr) }\end{array}$ & $\begin{array}{c}\text { Perubahan } \\
\text { produktivitas } \\
(\%)\end{array}$ & $\begin{array}{c}\text { Volume air } \\
\text { produksi (ltr) }\end{array}$ & $\begin{array}{c}\text { Produktivitas } \\
\text { air (gr/ltr) }\end{array}$ \\
\hline 1 & 119.70 & 27.50 & 29.83 & 10.03 & 11.93 \\
\hline 2 & 111.92 & 19.72 & 21.39 & 12.14 & 9.22 \\
\hline 3 & 83.08 & -9.13 & -9.90 & 12.05 & 6.89 \\
\hline 4 & 63.22 & -28.98 & -31.43 & 13.57 & 4.66 \\
\hline 5 & 101.84 & 9.64 & 10.46 & 13.42 & 7.59 \\
\hline 6 & 92.20 & 0.00 & - & 15.09 & 6.11 \\
\hline
\end{tabular}

Berdasarkan Tabel 3 menunjukkan bahwa variasi 1 dengan pemberian air irigasi setelah elevasi air mencapai kedalaman air $-5 \mathrm{~cm}$ menghasilkan produksi padi paling banyak dibandingkan dengan variasi yang lain yaitu rerata 119.70 gram. Kemudian diikuti variasi 2 yaitu ketika pemberian air irigasi setelah elevasi air mencapai kedalaman air $-10 \mathrm{~cm}$ sebesar 111.92 gram dan selanjutnya variasi 5 yaitu ketika pemberian air irigasi kombinasi dari berbagai kedalaman air sesuai dengan umur tanaman dengan hasil panen rata-rata 101.84 gram. Untuk variasi 6 yang pemberian air irigasinya secara konvensional menghasilkan padi rata-rata sebesar 92.20 gram. Untuk variasi 3 dan 4 yaitu ketika pemberian air irigasinya setelah elevasi air mencapai kedalaman air $-15 \mathrm{~cm}$ dan $-17 \mathrm{~cm}$ dari permukaan tanah menunjukkan penurunan produksi padi jika dibandingkan dengan variasi 6 metode konvensional yaitu dengan hasil panen rata-rata sebesar 69.68 gram dan 63.22 gram.

Sehingga dapat disimpulkan hasil panen padi variasi 1 pemberian air irigasi setelah kedalaman air mencapai $-5 \mathrm{~cm}$, variasi 2 pemberian air irigasi setelah kedalaman air mencapai -10 $\mathrm{cm}$ dan variasi 5 pemberian air irigasi merupakan kombinasi dari setelah kedalaman air mencapai berbagai elevasi sesuai dengan umur tanaman menunjukkan produksi hasil panen lebih banyak dibandingkan variasi 6 metodekonvensional. Sedangkan untuk variasi 3 pemberian air irigasi setelah kedalaman mencapai $-15 \mathrm{~cm}$ dan variasi 4 ketika pemberian air irigasi setelah kedalaman air mencapai $-17 \mathrm{~cm}$ hasil produksinya lebih kecil dibandingkan variasi 6 metode konvensional dan tidak disarankan untuk diaplikasikan.

Produktivitas air terbesar adalah variasi 1 yaitu pemberian air irigasi setelah kedalaman air mencapai elevai $-5 \mathrm{~cm}$ yaitu sebesar $11.93 \mathrm{gr} / \mathrm{lt}$, variasi yang lain produktivitas airnya masih lebih besar dari variasi 6 metode konvensional yaitu $6.11 \mathrm{gr} / \mathrm{lt}$, kecuali variasi 4 ketika pemberian air irigasinya setelah kedalaman air mencapai elevasi $-17 \mathrm{~cm}$ yaitu sebesar $4.66 \mathrm{gr} / \mathrm{lt}$.

\section{Kesimpulan}

Kondisi iklim selama penelitian relatif konstan dengan suhu rata-rata $26.20{ }^{\circ} \mathrm{C}$, kelembaban udara rata-rata $90.16 \%$, penguapan rata-rata 3.63 dan penyinaran matahari rata-rata $47.42 \%$. Berdasarkan hasil analisis dapat disimpulkan variasi 1 (kedalaman $-5 \mathrm{~cm}$ ) dan variasi 2 (kedalaman -10) $\mathrm{cm}$ dapat menghemat air $33.53 \%$ dan $19.55 \%$ dengan peningkatan hasil produksi $29.83 \%$ dan $21.39 \%$ jika dibandingkan dengan variasi 6 (metode konvensional). Variasi 3 (kedalaman -15 ) $\mathrm{cm}$ dan variasi 4 (kedalaman $-17 \mathrm{~cm}$ ) tidak disarankan diaplikasikan di lapangan karena walaupun dapat menghemat air $20.15 \%$ dan $10.07 \%$, namun hasil produksinya menurun $9.90 \%$ dan $31.43 \%$ apabila dibandingkan 
dengan variasi 6. Produktivitas air tertinggi variasi 1 yaitu $11.93 \mathrm{gr} / \mathrm{lt}$ disusul variasi 2 sebesar $9.22 \mathrm{gr} / \mathrm{lt}$, sedangan variasi 6 sebesar $6.11 \mathrm{gr} / \mathrm{lt}$.

\section{Daftar Pustaka}

Adriati, Y., and I. J. Sujono. 2008. "Kajian Beberapa Metode Sistem Pemberian Air Irigasi Padi Sawah.” Disertasi Doktor, Universitas Gadjah Mada.

Anugrah, I.S, Sumedi Sumedi, Wardana, I.P. 2008. "Gagasan Dan Implementasi System of Rice Intensification (SRI) Dalam Kegiatan Budidaya Padi Ekologis (BPE).” Analisis Kebijkan Pertanian 6(1): 75-99.

Chlarrasinta, U.F. 2018. "Analisis Koefisien Tanaman Padi Ciherang Pada Tiga Metode Pemberian Air Irigas.” Disertasi Doktor, Universitas Gadjah Mada.

Fuadi, Najla Anwar, Muhammad Yanuar J. Purwanto, and Suria Darma Tarigan. 2016. "Kajian Kebutuhan Air Dan Produktivitas Air Padi Sawah Dengan Sistem Pemberian Air Secara SRI Dan Konvensional Menggunakan Irigasi Pipa.” Jurnal Irigasi 11(1): 23-32.

Habibie, A. 2011. "Pengaturan Jarak Tanam Dan Irigasi Berselang (Intermittent Irrigation) Pada Metode SRI (System of Rice Intensification) Terhadap Produktivitas Tanaman Padi (Oryza Sativa L.) Varietas Ciherang.” Disertasi Doktor, Universitas Brawijaya.

Hilman. 2011. "Teknologi Hemat Air Di Lahan Sawah Irigasi, Balai Pengkajian Teknologi Pertanian Sulawesi Tenggara, Kendari” [Online] Available: http://sultra.litbang. pertanian.go.id/ ind/index.php?option=com_content\&view=article\&id=175:teknologi-hematair-di-lahan-sawah-irigasi\&catid=41:pertanian (accessed, September 15, 2020)

Kementerian Pertanian. 2020. "Pengelolaan Air Sistem Basah Kering (AWD)." http://sulsel.litbang.pertanian.go.id/ind/index.php/publikasi/panduan-petunjuk-teknisleaflet/103-pengelolaan-air-sistem-basah-kering-AWD (accessed, October 26, 2020).

Kurniadiningsih, Yanti. 2012. "Evaluasi Untung Rugi Penerapan Metode SRI (System of Rice Intensification) Di D.I Cihea Kabupaten Cianjur Jawa Barat.” Jurnal Akta Agrosia 18(7): 97.

Muh. Taufik Arafah, Nappu Basir, and Djufry Fadjry. 2014. "Analisis Pengelolaan Air Dalam Usaha Tani Padi Pada Lahan Sawah Irigasi Di Sulawesi Selatan.” Pengkajian dan Pengembangan Teknologi Pertanian (JPPTP) 7(1): 1-8. http://ejurnal.litbang.pertanian.go.id/index.php/jpengkajian/article/view/1382.

Munarso, Yuniati Pieter. 2011. "Keragaan Padi Hibrida Pada Sistem Pengairan.” Keragaan Padi Hibrida Sistem Pengairan Intermittent dan Tergenang 39(3): 77-83.

Rizal, Faisal, Alfiansyah YBC, and Maimun Rizalihadi. 2014. “Analisa Perbandingan Kebutuhan Air Irigasi Tanaman Padi Metode Konvensional Dengan Metode 'System of Rice Intensification' (SRI)”.” Teknik Sipil Pasca Sarjana Universitas Syiah Kuala 3(4): 67-76.

Sato Shuichi. 2007. "SRI mampu tingkatkan produksi Padi Nasional", (Online) http://www.merdeka.com/uang/sri-mampu-tingkatkan-produksi-padi-nasional-hqmffn6.html (accessed, Mei 18, 2016)

Sujono, J. 2012. "Koefisien Tanaman Padi Sawah Pada Sistem Irigasi Hemat Air." agriTECH 31(4): 344-51. 